\title{
R-Phase Structure Refinement Using Electron Diffraction Data
}

\author{
Dominique Schryvers and Pavel L. Potapov \\ EMAT, University of Antwerp, RUCA, Groenenborgerlaan 171, B-2020 Antwerp, Belgium
}

The atom positions in the structure of the R-phase in a TiNi(Fe) intermetallic compound have been refined using the multi-slice leastsquares method based on electron diffraction data obtained from $50 \mathrm{~nm}$ sized regions in a CM30 FEG TEM instrument. The refinement accounted for dynamic scattering including the specimen thickness and crystal misorientation as refining parameters. Compared with the original positions in the (111) planes of the parent B2 phase, each third Ti and Ni plane in the R-phase separates into three layers with different $z$-coordinates. This agrees with previous experiments in which it was concluded that the R-structure belongs to the space group $P 3$ rather than $P \overline{3} 1 \mathrm{~m}$ as determined earlier by convergent beam electron diffraction (CBED). However, our data reveal a centre of symmetry in the R-phase structure leading to the $P \overline{3}$ space group (R-factor of 5.5\%). Finally, it is suggested that the fine scale antiphase-like domains observed in the $\mathrm{R}$-phase appear due to mirror planes over which the above mentioned atomic shifts in the structure are reversed. This phenomenon is expected to cause an artificial symmetry increase in the space group determination when using CBED with a probe size close to the size of the domains.

(Received October 1, 2001; Accepted December 11, 2001)

Keywords: TiNi, titanium-nickel, R-phase, electron diffraction, transmission electron microscopy, structure refinement

\section{Introduction}

$\mathrm{Ti}-\mathrm{Ni}$ based intermetallic compounds with a $\mathrm{CsCl}(\mathrm{B} 2)$ austenite structure undergo a series of displacive phase transformations including martensitic ones to a variety of lower symmetry structures. One of those, the so called R-phase has a trigonal unit cell and was for a long time considered as an intermediate structure in the transformation path to the monoclinic B19' martensitic structure. Later, however, it was found that small additions of $\mathrm{Fe}$ separate the temperature ranges for $\mathrm{B} 2 \rightarrow \mathrm{R}$ and $\mathrm{B} 2 \rightarrow \mathrm{B} 19^{\prime}$ transformations by more than $100 \mathrm{~K}^{1)}$ The mechanism of the $\mathrm{B} 2 \rightarrow \mathrm{R}$ transformation has been described as a propagation of charge density waves ${ }^{2)}$ or as a condensation of the transverse phonon mode ${ }^{3)}$ in the parent B2 phase which result in the appearance of firstly an incommensurate superlattice ${ }^{2)}$ and then, at lower temperatures, the commensurate R-phase with a rhombohedral distortion of the initial cubic cell. ${ }^{4)}$ The term "R-phase" arises from the "Rhombohedral distortion", although later it has been established that its structure has a trigonal symmetry rather than a rhombohedral one. The space group of the R-phase has been initially determined as $P \overline{3} 1 \mathrm{~m}$ using convergent beam electron diffraction (CBED). ${ }^{5)}$ Recently, however, Hara et $\left.a l .{ }^{6}\right)$ refined the atomic positions in the R-phase based on its polycrystalline X-ray spectrum but also including selective dynamic information from electron scattering experiments. They found that the $\mathrm{Ti}$ and $\mathrm{Ni}$ atoms are located in much less symmetric positions than those expected for the $P \overline{3} 1 \mathrm{~m}$ group, suggesting the lower symmetry $P 3$ space group. However, the CBED patterns taken to confirm the lower symmetry still supported the $P \overline{3} 1 \mathrm{~m}$ group. ${ }^{6}$ )

The goal of the present work is to refine more accurately the atomic positions in the R-phase and clarify the controversy in the determination of its space group. For such a purpose nanoprobe electron diffraction patterns from small single crystalline areas in the R-phase have been analysed using the least-squares minimisation approach developed by Jansen et $a l .{ }^{7)}$ and Zandbergen et al. ${ }^{8)}$ In this approach, the dynamic scattering is fully taken into account and the specimen thick- ness and crystal misorientation are included in the list of refined parameters. The space group P3, i.e., the lowest possible symmetry in the trigonal system, was used for the initial refinement starting from the parent cubic positions assuming that any additional elements of symmetry, if existing, would be apparent from the refined atomic positions. Indeed, based on the initial results, the space group was changed to the more symmetric $P \overline{3}$ one in the final refinement.

\section{Experimental}

A $3 \mathrm{~mm}$ diameter rod of 50.75 at $\% \mathrm{Ti}-47.75$ at $\% \mathrm{Ni}-$ 1.50 at $\% \mathrm{Fe}$ alloy was produced by the Tokin Corporation and kindly provided by Dr. T. Hara and Prof. Dr. T. Ohba. The details of the alloy preparation and heat treatment are reported elsewhere. ${ }^{6)}$ The resulting samples reveal the commensurate $\mathrm{R}$-phase at room temperature as shown by X-ray examination and TEM.

The electron diffraction patterns used as input for the minimisation procedure were obtained at room temperature in a Philips CM30 microscope equipped with a field emission gun operating at $300 \mathrm{kV}$. A small probe size of about $50 \mathrm{~nm}$ in diameter was used to avoid overlapping of different orientation variants and also to reduce the variation of the thickness along the probe. For each region, this probe was scanned in the $x$ and $y$ directions over about $300 \mathrm{~nm}$ in steps of about $50 \mathrm{~nm}$, yielding an average of 25 patterns for each domain. The addition of the Fe results in stable R-phase material, not subject to any observable retransformation to the austenite due to electron beam heating in the extremely condensed probe. In order to observe sharp reflections instead of large discs the convergence of the beam was reduced by using the smallest condenser aperture. The patterns were recorded with a $1024 \times 1024$ pixel CCD camera and corrected for the camera gain reference and dark current. A very small microscope camera length was used to allow as many reflections as possible to enter the aperture in front of the CCD camera. The integral intensity of each reflection was extracted from the background and used for the refinement of the atomic po- 


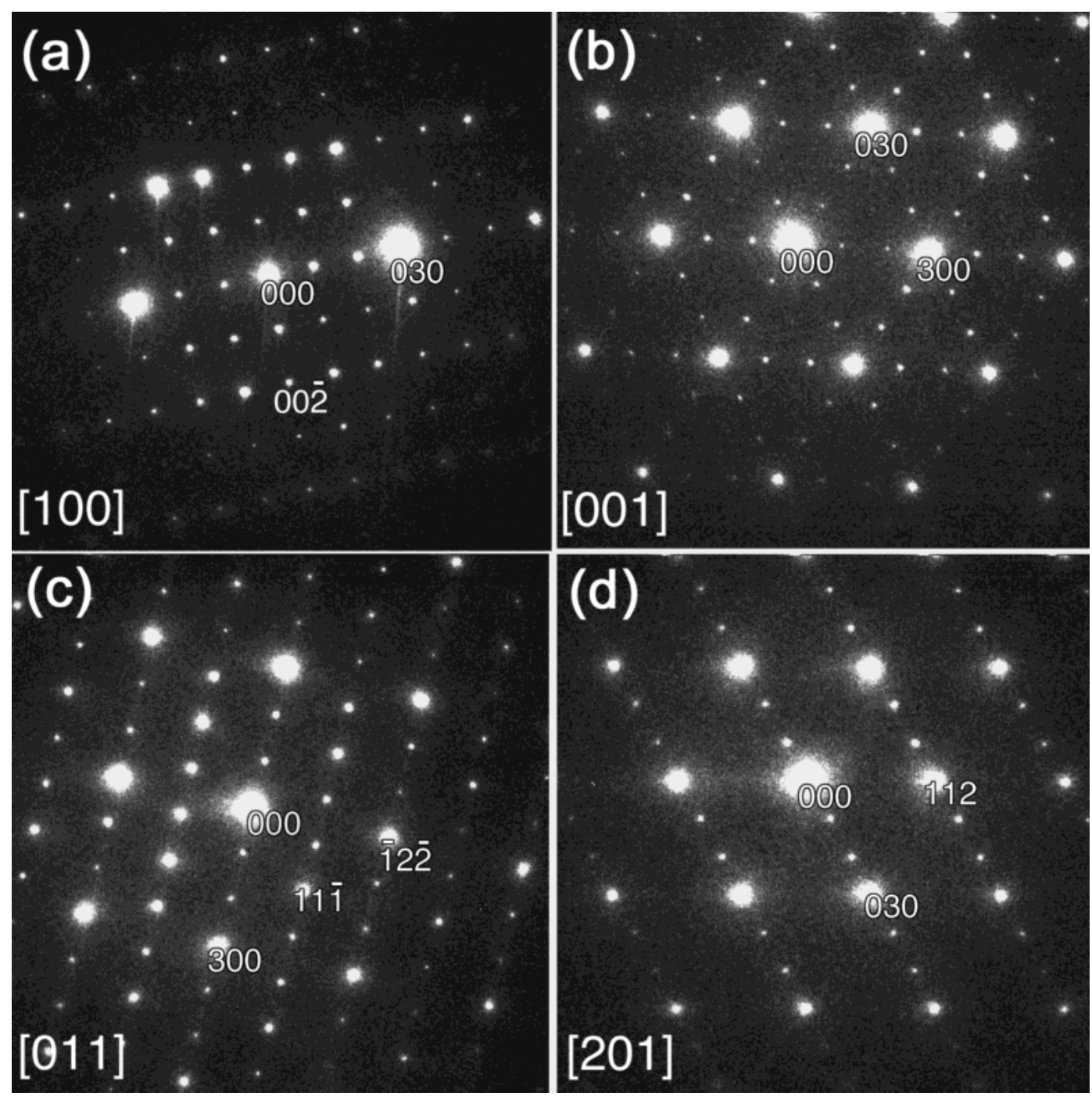

Fig. 1 Observed diffraction patterns in (a) [100], (b) [001], (c) [011] and (d) [201] orientation.

sitions. Only significant reflections having $I_{\mathrm{obs}}>2 \sigma\left(I_{\mathrm{obs}}\right)$ were used, which provided 30-60 reflections from each chosen pattern. The refinements were performed with the recently developed software package MSLS, ${ }^{7)}$ in which multislice calculation software is combined with least-square refinement software. In principle, the data treatment is thus very similar to that used in X-ray crystallography. The $\mathrm{R}$ value used in the refinements is $\Sigma\left|I_{\mathrm{obs}}-I_{\text {calc }}\right| / \Sigma I_{\mathrm{obs}}$. Details of typical pattern treatments can be found in Refs. 7) and 9).

\section{Results}

Figure 1 shows examples of the diffraction patterns collected in different zone orientations. All the patterns could be indexed using the trigonal unit cell of the R-phase using the lattice parameters $a=0.738 \mathrm{~nm}$ and $c=0.532 \mathrm{~nm}$ as suggested by Vatanayon et al. ${ }^{10)}$ Although qualitatively the patterns within a given series look very similar, the quantitative treatment of the reflection intensities reveals important variations of the patterns from probe to probe. Some of the diffraction patterns could be successfully refined using the $P 3$ space group, but $60-70 \%$ of the patterns failed to be refined, i.e. the final $\mathrm{R}$ factor was higher than $20 \%$. The situation is illustrated
Table $1 \mathrm{R}$ factor, thickness and misorientation for the series of the diffraction patterns obtained by scanning the $50 \mathrm{~nm}$ probe along the total area of $300 \mathrm{~nm}$. The zone is [100] along the entire area.

\begin{tabular}{rrrrrr}
\hline \multirow{2}{*}{$\begin{array}{c}\text { Probe } \\
\text { No. }\end{array}$} & \multirow{2}{*}{$\begin{array}{c}\mathrm{R} \\
\text { factor }\end{array}$} & $\begin{array}{c}\text { Refined } \\
\text { thickness }(\mathrm{nm})\end{array}$ & \multicolumn{3}{c}{ Refined crystal misorientation } \\
\cline { 5 - 6 } & & & $h$ & $k$ & \multicolumn{1}{c}{$k$} \\
\hline 1 & $8.9 \%$ & 18.1 & 0 & -0.49 & -0.71 \\
2 & $23.7 \%$ & 20.9 & 0 & 0.53 & -0.10 \\
3 & $92.8 \%$ & 19.7 & 0 & -0.23 & 1.20 \\
4 & $2.1 \%$ & 17.7 & 0 & -0.49 & -0.08 \\
5 & $14.0 \%$ & 16.3 & 0 & -0.53 & -0.76 \\
6 & $40.5 \%$ & 18.3 & 0 & -0.35 & -0.22 \\
7 & $7.5 \%$ & 19.3 & 0 & -0.31 & -0.67 \\
8 & $79.7 \%$ & 16.8 & 0 & -0.40 & 0.39 \\
9 & $24.7 \%$ & 18.7 & 0 & -0.32 & 0.47 \\
10 & $5.9 \%$ & 17.1 & 0 & -0.60 & 0.01 \\
11 & $26.0 \%$ & 18.3 & 0 & -0.29 & -0.50 \\
12 & $25.6 \%$ & 15.1 & 0 & -0.41 & -0.41 \\
13 & $3.6 \%$ & 17.7 & 0 & -0.43 & -0.43 \\
\hline
\end{tabular}

in Table 1 where the $\mathrm{R}$ factor of a series of patterns with the probe scanned over an area with the [100] orientation is presented. The strong variation of the $\mathrm{R}$ factor suggests that the 
Table $2 \mathrm{R}$ factor, thickness and misorientation for the 5 diffraction patterns refined in the $P 3$ space group.

\begin{tabular}{|c|c|c|c|c|c|c|}
\hline \multirow{2}{*}{ Zone } & \multirow{2}{*}{$\begin{array}{c}\text { Number of accounted } \\
\text { reflections }\end{array}$} & \multirow{2}{*}{$\mathrm{R}$ factor } & \multirow{2}{*}{$\begin{array}{l}\text { Refined thickness } \\
(\mathrm{nm})\end{array}$} & \multicolumn{3}{|c|}{ Refined crystal misorientation } \\
\hline & & & & $h$ & $k$ & $l$ \\
\hline 100 & 43 & $3.0 \%$ & 18.5 & 0 & 0.16 & 0.48 \\
\hline 001 & 28 & $6.4 \%$ & 7.7 & 0.02 & -1.20 & 0 \\
\hline 011 & 56 & $6.0 \%$ & 12.9 & 0.11 & 0.20 & -0.20 \\
\hline 201 & 32 & $1.9 \%$ & 9.4 & -0.51 & 1.91 & -1.01 \\
\hline
\end{tabular}

Total R factor $4.7 \%$

local atomic structure of the material varies within the scale of a few hundred nanometers. These results correlate with data by Hwang et al. who observed microdomains with a typical size of $150 \mathrm{~nm}$ in $\mathrm{Ti}_{50} \mathrm{Ni}_{47} \mathrm{Fe}_{3}$. ${ }^{4}$ ) Their morphology resembled "anti-phase-ordering domains", although Hwang et al. mentioned that those microdomains were associated rather with the variation of atomic structure and not with the variation of the ordering. In the further treatment, we assume that only those probes yielding an $\mathrm{R}$ factor below $15 \%$ represent the true single crystal R-phase while the remaining probes originate from boundary regions between the different structural domains and could thus be ignored for the present investigation. The possible nature of the microdomains will be discussed in the next section.

For the final refinement of the atomic structure of the Rphase, five diffraction patterns with different zone orientations and thickness were chosen as listed in Table 2. As a starting point, the initial atomic positions in the parent B2 phase were used, although no significant difference was observed when using the atomic positions obtained by Hara $e t$ $a l .{ }^{6)}$ as initial ones. The refinement assuming the $P 3$ space group for the structure results in an appropriate R-factor for each pattern as well as a good total $\mathrm{R}$ factor of $4.7 \%$. Table 3 lists the atomic coordinates refined in the $P 3$ space group. In agreement with the results by Hara et al., ${ }^{6)}$ the Ti atomic plane (positions $\mathrm{Ti}(1 \mathrm{a}), \mathrm{Ti}(1 \mathrm{~b}), \mathrm{Ti}(1 \mathrm{c})^{11)}$ ), having originally the $z=0$ coordinate in the parent phase, separates into three different planes with coordinates $z=0, z=-0.042$ and $z=-0.096$ in the R-phase. Similarly, the Ni atomic plane (positions $\mathrm{Ni}(1 \mathrm{a}), \mathrm{Ni}(\mathrm{b}), \mathrm{Ni}(1 \mathrm{c})$ ) with the original $z=0.5$ coordinate, separates into three planes with coordinates $z=0.441, z=0.491$ and $z=0.514$. As mentioned by Hara et al., ${ }^{6}$ such positions are not consistent with the $P \overline{3} 1 \mathrm{~m}$ space group which implies a mirror plane parallel to the $z$-direction and therefore, equal $z$-coordinates for Ti(1a), $\mathrm{Ti}(1 \mathrm{~b}), \mathrm{Ti}(1 \mathrm{c})$ and $\mathrm{Ni}(1 \mathrm{a}), \mathrm{Ni}(1 \mathrm{~b}), \mathrm{Ni}(1 \mathrm{c})$ atoms, respectively. This result was confirmed by attempting to refine the structure using the $P \overline{3} 1 \mathrm{~m}$ group and which was found to result in a noticeably higher total R-factor of about $8 \%$ as seen from Table 4. In Table 5 the obtained atomic coordinates for this symmetry are given for completeness.

There is, however, an important quantitative difference between our results and those obtained by Hara et al. for the $z$-positions of the $\mathrm{Ti}(1 \mathrm{a}), \mathrm{Ti}(1 \mathrm{~b}), \mathrm{Ti}(1 \mathrm{c})$ and $\mathrm{Ni}(1 \mathrm{a}), \mathrm{Ni}(1 \mathrm{~b})$, $\mathrm{Ni}(1 \mathrm{c})$ layers. Hara et al. reported that the interplane distance between $\mathrm{Ti}(1 \mathrm{a})$ and $\mathrm{Ti}(1 \mathrm{~b})$ layers is $0.083 \mathrm{c}$ while that between $\mathrm{Ti}(1 \mathrm{~b})$ and $\mathrm{Ti}(1 \mathrm{c})$ layers is only $0.009 \mathrm{c}$. Such a
Table 3 Atomic coordinates refined in the $P 3$ space group

\begin{tabular}{clllc}
\hline & $\begin{array}{l}\text { Multiplicity and } \\
\text { Wyckoff letter }\end{array}$ & $x$ & $y$ & $z$ \\
\hline $\mathrm{Ti}$ & 1a & 0 & 0 & 0 \\
& 1b & $1 / 3$ & $2 / 3$ & -0.096 \\
& 1c & $2 / 3$ & $1 / 3$ & -0.042 \\
& 3d & 0.353 & -0.007 & 0.303 \\
& 3d & 0.699 & -0.018 & 0.617 \\
\hline $\mathrm{Ni}$ & $1 \mathrm{a}$ & 0 & 0 & 0.514 \\
& $1 \mathrm{~b}$ & $1 / 3$ & $2 / 3$ & 0.441 \\
& $1 \mathrm{c}$ & $2 / 3$ & $1 / 3$ & 0.491 \\
& $3 \mathrm{~d}$ & 0.375 & 0.010 & 0.788 \\
& $3 \mathrm{~d}$ & 0.680 & 0.010 & 0.112 \\
\hline
\end{tabular}

Table $4 \mathrm{R}$ factor, thickness and misorientation for the 5 diffraction patterns refined in the $P \overline{3} 1 \mathrm{~m}$ space group.

\begin{tabular}{ccrrrrc}
\hline \multirow{2}{*}{ Zone } & $\begin{array}{c}\text { Number of } \\
\text { accounted } \\
\text { reflections }\end{array}$ & $\begin{array}{c}\mathrm{R} \\
\text { factor }\end{array}$ & $\begin{array}{c}\text { Refined } \\
\text { thickness } \\
(\mathrm{nm})\end{array}$ & \multicolumn{2}{c}{ Refined crystal misorientation } \\
\cline { 6 - 7 } 100 & 43 & $8.0 \%$ & 11.7 & 0 & 1.00 & -0.10 \\
100 & 56 & $18.2 \%$ & 16.7 & 0 & -1.11 & -0.07 \\
001 & 28 & $4.1 \%$ & 13.6 & -0.30 & -2.50 & 0 \\
011 & 56 & $7.7 \%$ & 13.1 & 0.33 & 0.24 & -0.24 \\
201 & 32 & $2.6 \%$ & 7.2 & -0.30 & 0.90 & -0.60 \\
\hline
\end{tabular}

Total R factor $8.1 \%$

Table 5 Atomic coordinates refined in the $P \overline{3} 1 \mathrm{~m}$ space group.

\begin{tabular}{lllll}
\hline & $\begin{array}{l}\text { Multiplicity and } \\
\text { Wyckoff letter }\end{array}$ & $x$ & $y$ & $z$ \\
\hline $\mathrm{Ti}$ & $1 \mathrm{a}$ & 0 & 0 & 0 \\
& $2 \mathrm{c}$ & $1 / 3$ & $2 / 3$ & 0 \\
& $6 \mathrm{k}$ & 0.362 & -0.032 & 0.294 \\
\hline $\mathrm{Ni}$ & $1 \mathrm{~b}$ & 0 & 0 & $1 / 2$ \\
& $2 \mathrm{~d}$ & $1 / 3$ & $2 / 3$ & $1 / 2$ \\
& $6 \mathrm{k}$ & 0.339 & -0.022 & 0.809 \\
\hline
\end{tabular}

big difference enabled them to assume that only the $\mathrm{Ti}(1 \mathrm{~b})$ atom is pushed out of the plane while $\mathrm{Ti}(1 \mathrm{a})$ and $\mathrm{Ti}(1 \mathrm{c})$ remain (within statistical errors) in the same plane. Similarly, they concluded that the $\mathrm{Ni}(1 \mathrm{a})$ and $\mathrm{Ni}(1 \mathrm{c})$ layers stayed in the same plane while the $\mathrm{Ni}(\mathrm{lb})$ layer was pushed out of this plane, although in the case of the Ni atoms, the observed in- 
Table $6 \mathrm{R}$ factor, thickness and misorientation for the 5 diffraction patterns refined in the $P \overline{3}$ space group.

\begin{tabular}{ccccccc}
\hline \multirow{2}{*}{ Zone } & $\begin{array}{c}\text { Number of } \\
\text { accounted } \\
\text { reflections }\end{array}$ & $\begin{array}{c}\text { R } \\
\text { factor }\end{array}$ & $\begin{array}{c}\text { Refined } \\
\text { thickness } \\
(\mathrm{nm})\end{array}$ & \multicolumn{2}{c}{ Refined crystal misorientation } \\
\cline { 5 - 7 } & & & \multicolumn{2}{c}{$h$} & $k$ & $l$ \\
\hline 100 & 43 & $6.1 \%$ & 23.2 & 0 & 0.26 & 0.70 \\
100 & 56 & $4.9 \%$ & 18.1 & 0 & -0.99 & -0.74 \\
001 & 28 & $4.6 \%$ & 8.9 & -0.30 & -3.10 & 0 \\
011 & 56 & $7.3 \%$ & 8.7 & 1.90 & 2.40 & -2.40 \\
201 & 32 & $4.9 \%$ & 4.4 & -0.90 & 0.70 & -2.00 \\
\hline
\end{tabular}

Total R factor $\quad 5.5 \%$

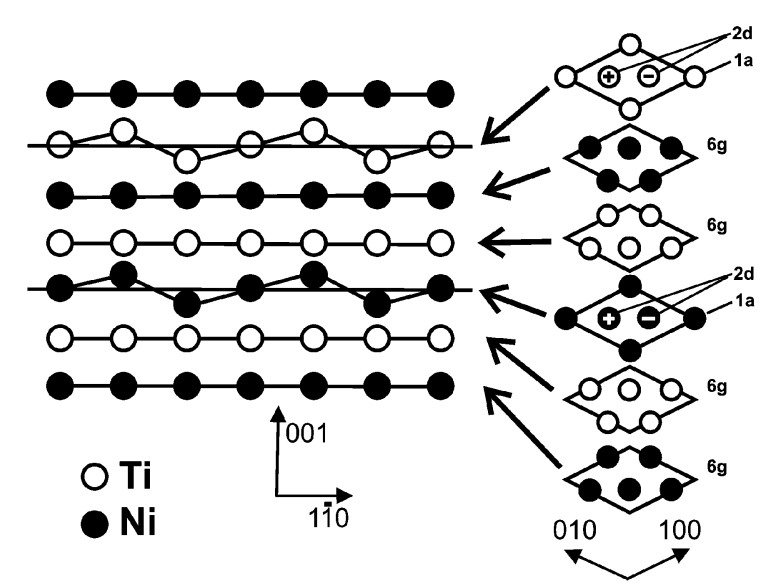

Fig. 2 Schematic illustration of the atomic layer positions in the $P \overline{3}$ model as viewed along (a) [110] and (b) in perspective. The Ti(1d) and Ni(1d) layers are shifted up and down, alternatively.

terplane distances $(0.084 \mathrm{c}$ for $\mathrm{Ni}(1 \mathrm{a})-\mathrm{Ni}(1 \mathrm{~b})$ and $0.061 \mathrm{c}$ for $\mathrm{Ni}(1 \mathrm{~b})-\mathrm{Ni}(1 \mathrm{c})$ ) do not clearly support such an assumption. In contrast, the present results indicate that the $\mathrm{Ti}(1 \mathrm{a})-\mathrm{Ti}(1 \mathrm{~b})$, $\mathrm{Ti}(1 \mathrm{~b})-\mathrm{Ti}(1 \mathrm{c}), \mathrm{Ni}(\mathrm{a})-\mathrm{Ni}(1 \mathrm{~b})$ and $\mathrm{Ni}(1 \mathrm{~b})-\mathrm{Ni}(1 \mathrm{c})$ interplane distances vary in a much smaller range between $0.023 \mathrm{c}$ and $0.054 \mathrm{c}$. Moreover, for the $\mathrm{Ti}$ as well as $\mathrm{Ni}$ atoms, the (1a) layer shifts up and the (1b) layers shifts down almost symmetrically relative to the (1c) layer. This fact probably indicates the presence of a centre of symmetry in the structure. Indeed, a following refinement using the $P \overline{3}$ space group results in a total $\mathrm{R}$ factor of $5.5 \%$ as seen from Table 6 , which is only slightly higher than that for the $P 3$ group in Table 2. As the $P 3$ group is a subgroup of the $P \overline{3}$ one and therefore has additional degrees of freedom in the variation of atomic coordinates, a slightly lower R factor for the $P 3$ group compared with the $P \overline{3}$ one can be the result of statistical errors. Thus, the $P \overline{3}$ group is selected as the most probable space group of the $\mathrm{R}$ structure. Introducing the $1.5 \% \mathrm{Fe}$ atoms on the Ni sublattice, does not noticeably change the results of the refinement.

The final atomic positions refined in the $P \overline{3}$ group are listed in Table 7 and illustrated in Fig. 2. Comparing with the original positions in the parent phase, each third $\mathrm{Ti}$ and $\mathrm{Ni}$ plane in the R-phase separates into three layers with different $z$ coordinates. Two layers (2d) shift from the original plane up and down correspondingly with a shift value of about $0.05 \mathrm{c}$ while the third layer (1a) stays in the plane. The structure is centrosymmetic with the centre of symmetry located at a
$\mathrm{Ti}(1 \mathrm{a})$ or Ni(1a) atom. The other Ti and Ni planes (6g) are not affected and stay at approximately the same $z$-positions as those in the parent phase. At least, their shifts along the $z$-direction are 3 times smaller than those of the (2d) layers. The obtained shifts of $(6 \mathrm{~g})$ atoms in the $x$ - and $y$-directions are also very small and no clear regularities in their arrangement can be found.

\section{Discussion}

Originally the space group of the R-phase was determined by CBED as $P \overline{3} 1 \mathrm{~m},{ }^{5)}$ although later Hara et al., ${ }^{6)}$ on the basis of X-ray refinement and selected electron diffraction, reported that it belongs to the $P 3$ one. At this point, it should be mentioned that Hara et al. presented the R factor in two definitions: " $R_{\mathrm{p}}$ " and " $R_{\mathrm{p}}$ (peak)". The former depends strongly on the polycrystalline background scattering and is used solely for the comparison among polycrystalline X-ray patterns. The latter is independent of the background and can be roughly compared with the $\mathrm{R}$ factor observed from single crystalline patterns, as our nanoprobe single crystal electron diffraction patterns. Both values $\left(R_{\mathrm{p}}=6 \%\right.$ and $R_{\mathrm{p}}($ peak $\left.)=24 \%\right)$ were higher that those normally adopted for a well refined structure, thus the precision of the results of Hara et al. is relatively low. One reason for this, as already mentioned by Hara et al. ${ }^{6)}$ was the fibered texture of the samples, which distorted the ratio among the peak intensities in the X-ray analysis. Another reason could be the presence of a small amount of the $\mathrm{B} 19^{\prime}$ martensite in the R matrix. In the present work, the same material as in ${ }^{6}$ ) was used, and some traces of the B19' martensite were indeed occasionally detected by TEM. Figure 3 shows the appearance of extra reflections in the diffraction pattern of the R-phase after a shift of the probe of about hundred nanometers. The additional reflections can be explained by the presence of the B $19^{\prime}$ martensite. Such small precursors of B19' martensite were not detected by the X-ray analysis although they could contribute in the R-phase peak intensities and thus distort a refinement based on polycrystalline $\mathrm{X}$-ray data. Another argument of Hara et al. in favour of the $P 3$ space group was the multislice dynamical calculations of the electron diffraction, which qualitatively fitted the experimental patterns. ${ }^{6}$ ) We have, however, found that even small changes in atomic positions can reverse the calculated ratio between the strongest and smallest reflections, indicating that such a qualitative comparison based on a few reflections and without proper knowledge of the sample thickness should be taken with exteme care.

In the present work, the atomic positions were refined yielding an $\mathrm{R}$ factor of about $5 \%$ which is much better than the comparable value of Hara $\left(R_{\mathrm{p}}(\mathrm{peak})=24 \%\right) .{ }^{6)}$ Nevertheless, our results confirm the conclusion by Hara et al. that the symmetry of the R-phase is lower than that of the $P \overline{3} 1 \mathrm{~m}$ group. However, the improved accuracy used in our experiments reveals that the atoms in the R-phase structure are located in centrosymmetric positions or at least near to those, leading to the $P \overline{3}$ space group instead of the $P 3$ one. At the same time, the accuracy of our method is limited as the unknown thickness and misorientation of each diffraction pattern add additional parameters to be refined by the program. Probably due to this reason, we could not find any logic regularities 
Table 7 Atomic coordinates refined in the $P \overline{3}$ space group.

\begin{tabular}{|c|c|c|c|c|c|c|c|}
\hline & \multirow{2}{*}{$\begin{array}{l}\text { Multiplicity and } \\
\text { Wyckoff letter }\end{array}$} & \multirow{2}{*}{$x$} & \multirow{2}{*}{$y$} & \multirow{2}{*}{$z$} & \multicolumn{3}{|c|}{$\begin{array}{l}\text { Deviation from the positions } \\
\text { in the parent B2 structure }\end{array}$} \\
\hline & & & & & $\Delta x$ & $\Delta y$ & $\Delta z$ \\
\hline \multirow[t]{3}{*}{$\mathrm{Ti}$} & $1 \mathrm{a}$ & 0 & 0 & 0 & - & - & - \\
\hline & $2 d$ & $1 / 3$ & $2 / 3$ & 0.045 & - & - & 0.045 \\
\hline & $6 g$ & 0.346 & -0.002 & 0.346 & 0.013 & -0.002 & 0.013 \\
\hline \multirow[t]{3}{*}{$\mathrm{Ni}$} & $1 \mathrm{a}$ & 0 & 0 & $1 / 2$ & - & - & - \\
\hline & $2 d$ & $1 / 3$ & $2 / 3$ & 0.547 & - & - & 0.047 \\
\hline & $6 \mathrm{~g}$ & 0.332 & -0.008 & 0.815 & -0.001 & -0.008 & -0.018 \\
\hline
\end{tabular}

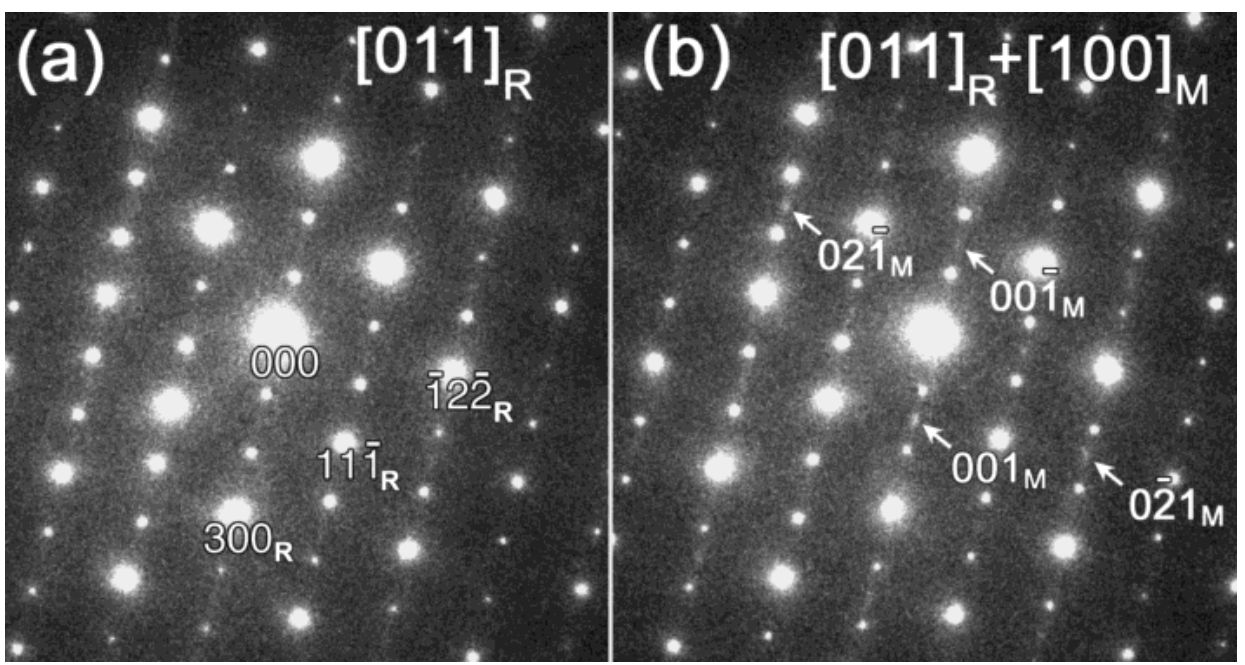

Fig. 3 Variation of the nanoprobe diffraction pattern obtained by scanning the $50 \mathrm{~nm}$ probe along the total area of $300 \mathrm{~nm}$. The R-phase zone orientation is [100]. The weak traces of the martensitic B19' reflections are seen in (b).

in the refined shifts of the atoms in the $x$ - and $y$-directions, which seem to be too small for measuring reliably with the current method.

The structure of the $\zeta_{2}^{\prime}$ phase in Au-Cd alloys has been for years believed to be similar to the R-phase one. Comparing the present data on R-TiNi with results of the single crystal $\mathrm{X}$-ray analysis of $\zeta_{2}^{\prime}$-AuCd ${ }^{12)}$ reveals similar structural features as well. In both $\zeta_{2}^{\prime}$ - and R-structures, each third original $(111)_{\mathrm{B} 2}$ plane separates into several layers. However, for $\zeta_{2}^{\prime}$, one atom is pushed out of the $(111)_{\mathrm{B} 2}$ plane yielding the $P 3$ space group, while in the R-phase, two atoms are pushed symmetrically in opposite directions leading to the $P \overline{3}$ space group. The difference can be related with the different combination of the $\{100\}[110]$ displacement waves involved in the $\mathrm{B} 2 \rightarrow \mathrm{R}\left(\zeta_{2}^{\prime}\right)$ transformations. ${ }^{3)}$

Finally, we suggest a possible structural reason for the inconsistency between the results of atomic positions refinement and the symmetry determination by CBED. Both in Refs. 5) and 6), the CBED pattern in the [001] orientation showed the diffraction group $6_{\mathrm{R}} m m_{\mathrm{R}}$ which supports the space group $P \overline{3} 1 \mathrm{~m}$ with mirror planes parallel to the [001] axis. In contrast, the refinement of the atomic positions in ${ }^{6}$ ) as well as in the present work declines the presence of such mirror planes. We should, however, mention that the $P \overline{3}$ space group allows the appearance of mirrored antiphase domains as sketched in Fig. 4. Such domains can coherently match each other along $\{100\}$ planes, which serve as mirror

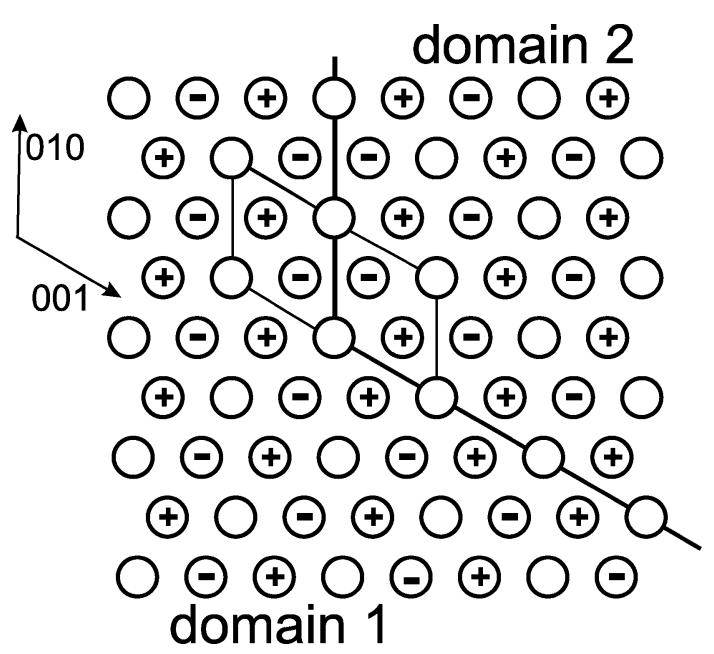

Fig. 4 Antiphase domains allowed by the $P \overline{3}$ model. Only the Ti plane viewed along the [001] direction is shown. The "+" and "-" denote the shift of atoms above and below the plane, respectively. The unit cells outlined by thin lines are mirrored in domain 1 and domain 2 . Antiphase $\{100\}$ boundaries depicted by the thick lines serve as a mirror planes among the neighbouring domains.

planes between the neighbouring domains. This model explains successfully the structural nature of antiphase domains with a typical size of $150 \mathrm{~nm}$ and experimentally observed by Hwang et l. $^{4)}$ In CBED, a probe of comparable size is normally applied, thus the resulting pattern would result from a number of mirrored domains. In such conditions, a false 
mirror plane parallel to one or two $\langle 100\rangle$ directions might be observed in the CBED pattern.

\section{Conclusions}

Based on a least-squares minimisation procedure using dynamic electron diffraction data as input, the space group of the R-phase structure in $\mathrm{Ti}_{50.75} \mathrm{Ni}_{47.75} \mathrm{Fe}_{1.50}$ is found to be the $P \overline{3}$ one. The centrosymmetric nature relates to symmetric shifts of $\mathrm{Ti}$ and $\mathrm{Ni}$ atoms out of the original $\{111\}$ planes in the parent B2 structure. Mirror planes parallel to the $z$-direction and observed in earlier CBED patterns are explained as an artifact due to the presence of antiphase-like microdomains.

\section{Acknowledgements}

The help of Dr. T. Hara and Prof. Dr. T. Ohba for providing the R-phase material is most greatly appreciated. Dr. J. Janssen is acknowledged for the support in the use of the MSLS software. Part of this work is performed in the framework of the IUAP project "Reduced Dimensionality Systems" with contract number $\mathrm{P} 4 / 10$.

\section{REFERENCES}

1) M. Matsumoto and T. Homma: Proc. 1st Int. Symp. on Martensite, (JIM, Kobe, 1976) pp. 199-204.

2) C. M. Hwang, M. Meichle, M. B. Salamon and C. M. Wayman: Philos. Mag. 47 (1983) 9-30.

3) S. M. Shapiro, Y. Noda, Y. Fujii and Y. Yamada: Phys. Rev. B 30 (1984) 4314-4321.

4) C. M. Hwang, M. Meichle, M. B. Salamon and C. M. Wayman: Philos. Mag. 47 (1983) 31-62.

5) E. Goo and R. Sinclair: Acta Metall. 33 (1985) 1717-1723.

6) T. Hara, T. Ohba, E. Okunishi and K. Otsuka: Mater. Trans., JIM 38 (1997) 11-17.

7) J. Jansen, D. Tang, H. W. Zandbergen and H. Schenk: Acta Crystallogr. A54 (1998) 91-101.

8) H. W. Zandbergen, E. van Zwet, J. Jansen, J. C. Sarrac, M. B. Mapple and R. J. Cava: Philos. Mag. Lett. 71 (1995) 131-138.

9) J. Jansen and H. W. Zandbergen: J. Microscopy 19 (1998) 222-237.

10) S. Vatanayon and R. F. Hehemann: in Shape Memory Effect in Alloys, Ed. by J. Perkins (Plenum Press: New York, 1975) pp. 115-120.

11) International Tables For Crystallography, ed. T. Hahn., Dordrecht, Holland: D. Reidel Publishing Co. A (1983) pp. 480-481.

12) T. Ohba, Y. Emura and K. Otsuka: Matar. Trans., JIM 33 (1992) 29-37. 